\title{
Ato administrativo e indeterminabilidade do direito in abstracto: da aplicação do princípio da boa administração
}

rdai.com.br/index.php/rdai/article/view/rodrigues19

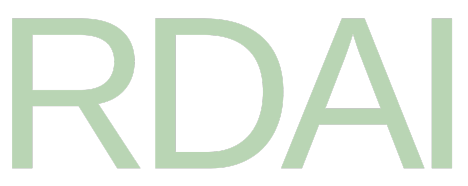

\section{Autores}

- Rafael de Oliveira Rodrigues Pontifícia Universidade Católica de São Paulo - PUCSP (São Paulo, São Paulo, Brasil).

- Braulio Bata Simões Pontifícia Universidade Católica de São Paulo (São Paulo, São Paulo, Brasil)

\section{DOI:}

https://doi.org/10.48143/rdai.19.ror

\section{Palavras-chave:}

Aplicação do direito, Conceitos jurídicos indeterminados, Discricionariedade, Princípio da boa administração

\section{Resumo}

A complexidade das relações sociais impõe o reconhecimento da impossibilidade de previsão de todas as situações fáticas passíveis de descrição na hipótese normativa "in abstracto". Nesse sentido, o legislador passou a empregar uma série de técnicas legislativas que, visto providas de substancial grau de indeterminabilidade, têm o poder de aumentar consideravelmente o alcance da norma jurídica. A tendência acima descrita tem especial repercussão nas relações jurídicas que envolvam o Estado. Nesses casos, atribui-se ao administrador público uma maior amplitude para a aplicação do direito (visto que não mais se faz por automática subsunção). No entanto, na mesma medida em que se dá a ampliação da atribuição de aplicar o direito ao caso concreto, exige-se uma maior responsabilidade ao atingimento da finalidade estabelecida na norma aplicada. Nesse quadro, é de se reconhecer que haverá casos aos quais a aplicação desse expediente utilizado pelo legislador não apresentará uma única resposta justa e razoável pelo direito. O resultado disso é a aproximação da atividade estatal, no caso, à competência discricionária. É necessário, todavia, que se identifiquem os limites que o Direito impõe à atividade administrativa no que concerne à sua aplicação, de forma que a Administração 
Pública não se utilize indevidamente do ordenamento com o escopo de mascarar arbitrariedade. Com isso, o princípio da boa administração apresenta relevante papel norteador da atividade estatal.

\section{Biografia do Autor}

\section{Rafael de Oliveira Rodrigues, Pontifícia Universidade Católica de São Paulo - PUC-SP (São Paulo, São Paulo, Brasil).}

Mestre em Direito pela Pontifícia Universidade Católica de São Paulo - PUC-SP (São Paulo, São Paulo, Brasil). Especialista em Direito Tributário pela Escola Superior da Procuradoria-Geral do Estado de São Paulo e em Direito Processual Civil pela Pontifícia Universidade Católica de São Paulo, PUC-SP. Atua como procurador na PGE-SP Procuradoria Geral do Estado de São Paulo.

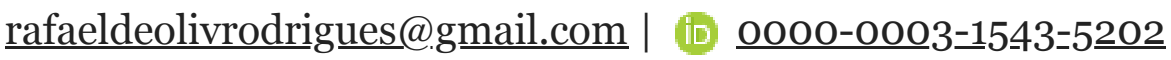

\section{Braulio Bata Simões, Pontifícia Universidade Católica de São Paulo (São Paulo, São Paulo, Brasil)}

Doutor em Direito pela Pontifícia Universidade Católica de São Paulo - PUC-SP (São Paulo, São Paulo, Brasil), onde também cursou o estágio de pesquisa de pós-doutorado e titulou-se mestre. É docente no PPGD do Centro de Estudos de Direito Econômico e Social - CEDES. Na pós-graduação realizou estágio de pesquisa como Visiting Researcher na International Bureau of Fiscal Documentation (IBFD - Amsterdam) e especialização em LL.M.-Direito Societário (INSPER), Direito Tributário (USP), Direito Processual (PUC-SP), MBA em Legal Administration (EPD), International Tax Law (ITC Holanda), Teoria Geral do Direito (IBET), Direito (FGV-SP). A pesquisa está na área direito tributário. É membro integrante do Instituto Brasileiro de Direito Tributário, da Associação Brasileira de Direito Fiscal e da International Fiscal Association. (DD ooooo002-1077-9.73으 | bata@ $\underline{\text { bsplaw.com.br }}$

\section{Referências}

ALESSI, Renato. Instituciones de derecho administrativo. Buenos Aires: Casa Editorial, 1990.

BACIGALUPO, Silvina. Delitos de infração de dever e acessoriedade no direito penal. In: OLIVEIRA, William Terra de; LEITE NETO, Pedro Ferreira; ESSADO, Tiago Cintra e SAAD-DINIZ, Eduardo (Org.). Direito penal econômico: estudos em homenagem aos 75 anos do professor Klaus Tiedemann. São Paulo: LiberArs, 2013.

BANDEIRA DE MELLO, Celso Antônio. Elementos de direito administrativo. São Paulo: Malheiros, 2017.

BATTAGLINI, Cosi Orsi. Attività vincolata e situazioni soggettive. Padova: Daltricce, 2004 . 
BIELSA, Rafael. Derecho administrativo. Buenos Aires: La Ley, 1975.

BITENCOURT NETO, Eurico. Improbidade administrativa e violação de princípios. Belo Horizonte: Del Rey, 2005.

BONNARD, Roger. Précis de Droit Administratif. Paris: Libraire du Recueil Sirey, 1993.

BRANDÃO, Antônio José. Moralidade administrativa. Revista de Direito Administrativo, Rio de Janeiro, v. 25, jul.-set. 1951.

BUENO, Eduardo. A coroa, a cruz e a espada: lei, ordem e corrupção no Brasil colônia. Rio de Janeiro: Objetiva, 2006.

CARVALHO FILHO, José dos Santos. Manual de direito administrativo. Rio de Janeiro: Lumen Juris, 2006.

CAVALCANTI, Themístocles Brandão. Tratado de direito administrativo. São Paulo: Freitas Bastos, 1986.

DAL BOSCO, Maria Goretti. Responsabilidade do agente público por ato de improbidade. Rio de Janeiro: Lumen Juris, 2004.

DECOMAIN, Pedro Roberto. Improbidade administrativa. São Paulo: Dialética, 2007.

DI PIETRO, Maria Sylvia Zanella. Discricionariedade administrativa na Constituição de 1988. São Paulo: Atlas, 1991.

DI PIETRO, Maria Sylvia Zanella. Direito administrativo. São Paulo: Atlas, 2005.

DWORKIN, Ronald. Justice for Hedgehogs. Cambridge: Harvard University Press, 2011.

FAZZIO JUNIOR, Waldo; PAZZAGLINI FILHO, Marino; ROSA, Márcio Fernandes Elias. Improbidade administrativa. São Paulo: Atlas, 1999.

FRANCO SOBRINHO, Manoel de Oliveira. O princípio constitucional da moralidade administrativa. Curitiba: Genesis Editora, 1993.

FIGUEIREDO, Lucia Valle. Curso de direito administrativo. São Paulo: Malheiros, 1999.

FIGUEIREDO, Marcelo. O controle da moralidade na Constituição. São Paulo: Malheiros, 1999.

FORNACIARI JUNIOR, Clito. Prescrição das ações de ressarcimento de danos causados por ato de improbidade administrativa. Revista de Informação Legislativa, Brasília, v. 165, p. 34-35, 2005 .

GABARDO, Emerson. A nova decisão do STF sobre a imprescritibilidade do ressarcimento ao erário por ato de improbidade. Direito do Estado, n. 409, edição de 11.08.2018. Disponível em:[www.direitodoestado.com.br/colunistas/emerson-gabardo/anova-decisao-do-stf-sobre-a-imprescritibil Acesso em: 27.10.2020. 
GARCIA, Emerson; ALVES, Rogério Pacheco. Improbidade administrativa. Rio de Janeiro: Lumen Juris, 2002.

GARCIA, Emerson. Improbidade administrativa: configuração e reparação do dano moral. Revista da EMERJ, v. 12, n. 48, 2009.

GOMES, Emerson C. S. Responsabilidade financeira: uma teoria sobre a responsabilidade no âmbito dos tribunais de contas. Porto Alegre: Núria Fabris, 2012.

GRECO, Guido. Argomenti di Diritto Amministrativo. Milano: Giuffrè, 2002.

GRONDIN, Jean. Introdução à hermenêutica filosófica. São Leopoldo: Unisinos, 1999.

HAURIOU, Maurice. Précis de Droit Administratif et de Droit Public. Paris: Recueil Sirey, 1920.

KINDHÄUSER, Urs. Derecho penal de la culpabilidad y conducta peligrosa. Bogotá: Universidad Externado, 1996.

LEAL, Rogerio Gesta. Estado, administração pública e sociedade: novos paradigmas. Porto Alegre: Livraria do Advogado, 2006.

LEAL, Rogerio Gesta. Patologias corruptivas nas relações entre estado, administração pública e sociedade: causas, consequências e tratamentos. Santa Cruz do Sul: Edunisc, 2013 .

LIMA, Ruy Cirne. Princípios de direito administrativo. Porto Alegre: Globo, 1984.

MORIN, Gastón. La revolte des fait contre le Code. Paris: FDL, 1990.

OSÓRIO, Fábio Medina. Teoria da improbidade administrativa: má gestão pública, corrupção e ineficiência. São Paulo: Ed. RT, 2007.

PAOLO, Mauro. Corruption and Growth. Quarterly Journal of Economics, v. 110, p. 681712, ago. 1995 .

PAZZAGLINI FILHO, Marino; ROSA, Márcio Fernando Elias; FAZZIO JR., Waldo. Júnior Improbidade administrativa: aspectos jurídicos na defesa do patrimônio público. São Paulo: Atlas, 1999.

PRADO, Francisco Octávio de Almeida. Improbidade administrativa. São Paulo: Malheiros Editores, 2001.

RIPERT, George. La régle morale dans les obligations civiles. Paris: Dalloz, 1984.

ROTHEBURG, Walter Claudius. Acão de improbidade administrativa: aspectos de relevo. In: SAMPAIO, José Adércio Leite et al. (Org.). Improbidade administrativa:

comemoração pelos 10 anos da Lei 8.429/92 (LGL199219). Belo Horizonte: Del Rey, 2002. 
SILVA, José Afonso da. Curso de direito constitucional positivo. São Paulo: Malheiros, 2005 .

TOURINHO, Rita Andréa Rehem Almeida. A prescrição e a Lei de Improbidade Administrativa. Disponível em: [https://jus.com.br/artigos/5054/a-prescricao-e-a-lei-deimprobidade-administrativa] Acesso em: 03.11.2020.

\section{Como Citar}

RODRIGUES, R. de O. .; SIMÕES, B. B. Ato administrativo e indeterminabilidade do direito in abstracto: da aplicação do princípio da boa administração: Administrative act and the undetermined law "in abstracto": the application of the good administration principle. Revista de Direito Administrativo e Infraestrutura | RDAI, São Paulo: Thomson Reuters - Livraria RT, v. 5, n. 19, p. 47-70, 2022. DOI: 10.48143/rdai.19.ror. Disponível em: https://rdai.com.br/index.php/rdai/article/view/rodrigues19. Acesso em: 7 fev. 2022.

\section{Edição}

V.5_n. 19_(2021).

\section{Seção}

Ato Administrativo

\section{Licença}

Copyright (c) 2021 Revista de Direito Administrativo e Infraestrutura - RDAI

\section{c) (i) $\ominus$}

Este trabalho está licenciado sob uma licença Creative Commons Attribution-

NonCommercial-NoDerivatives 4.0 International License.

(CC BY-NC-ND).

Este é um resumo (e não um substituto) da licença

Regras para publicação

Direitrizes Editoriais

Direitos e Deveres

Errata e Retratação

Preservaçãa e Plagiarismo

Revisão e Avaliação 
